\title{
Conceptual causal models of socioeconomic status, family structure, family functioning and their role in public health
}

Frederik Booysen ${ }^{1 *}$, Ferdi Botha ${ }^{2,3}$ and Edwin Wouters ${ }^{4}$

\begin{abstract}
Social determinants of health frameworks are standard tools in public health. These frameworks for the most part omit a crucial factor: the family. Socioeconomic status moreover is a prominent social determinant of health. Insofar as family functioning is poorer in poor families and family structure and functioning are linked to health, it is critical to consider the pathways between these four constructs. In this correspondence, we reflect on how empirical studies of this conceptual nexus mirror two causal models. We conclude by reflecting on future directions for research in this field.
\end{abstract}

Keywords: Social determinants of health, Family structure, Family functioning, Socioeconomic status

\section{Introduction}

Social determinants of health $(\mathrm{SDH})$ frameworks are standard tools in informing researchers, practitioners and policymakers of the underlying role of social factors in improving public health [1]. The World Health Organization's (WHO) Commission on the Social Determinants of Health defined SDH as "the conditions in which people are born, grow, live, work and age" and "the fundamental drivers of these conditions" [2]. The impact of these $\mathrm{SDH}$ on health outcomes have been repeatedly demonstrated $[3,4]$. As a response, the WHO developed a 'Conceptual Framework for Action on the Social Determinants of Health'. This framework outlines the structural determinants of health inequities both at the macro (socio-economic and political context) and micro (social class, gender and ethnicity) level. The model further stipulates that these SDH operate through a set of

\footnotetext{
* Correspondence: frederik.booysen@wits.ac.za

School of Economics and Finance, University of the Witwatersrand 1 Jan Smuts Avenue, Braamfontein 2050 Johannesburg South Africa Full list of author information is available at the end of the article
}

intermediary determinants of health, namely: (1) material circumstances; (2) psychosocial circumstances; (3) behavioural and/or biological factors; and (4) the health system itself [5]. However, despite the wealth of research on how health plays out in family and household contexts, we argue that theoretical discussions surrounding this framework for the most part omits explicit reference to a crucial but complex social factor that affects and is affected by health: the family.

\section{The family context}

Individuals seldomly live in total isolation: the family context in which people eat, sleep and live could be both a structural determinant (family structure) as well as an intermediary determinant (family functioning) of health and even be affected by health. Families can have very different structures (nuclear, skip-generation, single parent, etc.), which have been shown to be a structural driver of the mental health of family members and especially children [6]. However, not only the structure of families can impact health. For families to fulfil their 
roles in society, families need to function well. Formally, family functioning encompasses the ability of the family to accomplish the tasks necessary to achieve its wellbeing, the ability to adapt to changing circumstances, and the ability to balance individual family members' needs with those of the family system [7]. Theoretically, the relationship of family functioning with health is reciprocal and complex in nature. Ill health may adversely affect family functioning [8]. Health stressors may however also unlock the family's resilience and result in improvements in family functioning [9]. Members of wellfunctioning families may also enjoy better physical and mental health due to the greater instrumental and emotional support available to them [10], whereas dysfunction may result in the maintenance of poor health behaviours [11].

The body of empirical evidence on health and family functioning documented in reviews provide considerable support for claims of such an association, including in regard to overweight and obesity in children and adolescents [12], disability in children [13] and pediatric organ transplants [14]. A recent meta-analysis has found evidence of a significant association between less family conflict and greater family cohesion, expressiveness and support, and adjustment in pediatric cancer patients and their siblings [15]. Other recent meta-analyses suggest that the psychological health of children with chronic conditions is associated with many dimensions of family functioning, in particular conflict and cohesion [16], as is the case for medical adherence, especially regarding better problemsolving, positive communication, greater cohesion and flexibility, and less conflict [17]. Yet, in other instances, evidence has been lacking or mixed, including in regard to eating disorders [11], service use by young people with mental health issues [18], and childhood cancer [9]. The most prominent multi-dimensional measures of family functioning employed across these studies, which are grounded in diverse theoretical frameworks, include the McMaster Family Assessment Device (FAD), the Family Assessment Measure (FAM), the Family Environment Scale (FES) and the Family Adaptability and Cohesion Evaluation Scale (FACES) [11-14, 16].

Only recently, however, have scholars proceeded to explicitly conceptualise the family's role as a SDH $[19,20]$. One proposed approach has been to consider family structure as a structurally-determined and socially stratified grouping [21]. Another possibility, in respect of family functioning, is to consider it among the intermediary determinants as a specific psychosocial factor. There is evidence, moreover, albeit mixed, that poorer family functioning is associated with family structure, including family intactness and family configurations such as single parenthood and cohabitation [22-33].

\section{Proposed conceptual causal models}

Socioeconomic status (SES), moreover, conceptualised broadly, is a prominent SDH. Insofar as family functioning has been shown to be poorer in families with lower SES [34-38], it is critical to consider the pathways between these constructs, i.e. socioeconomic status, the family (composed of family structure and functioning) and health. Drawing on the work of $\mathrm{Wu}$ and Zumbo [39], we offer some suggestions in the form of two sets of simplified causal models.

Assuming that the focus, on the one hand, is on the causal link between family structure $(\mathrm{X})$ and health $(\mathrm{Y})$, we could describe family functioning as a potential mediator (Me) that answers the question as to how and why family structure impacts on health. In turn, SES (Mo) may moderate both the causal link between family structure and family functioning as well as the causal link between family functioning and health (Fig. 1a). Family functioning may also mediate the causal interactive effect between family structure and SES (Fig. 2a).

On the other hand, Fig. 1b and Fig. 2b for each causal model recognises that health may also impact family functioning and family structure and that socioeconomic status may moderate these effects. Caution is required however insofar as family structure in the longer term is fluid too and that family functioning may be a function of family structure. The implication is that family structure may also be treated as a mediator rather than a moderator. The same applies to SES, which underlines the fact that further efforts at building appropriate and comprehensive causal models are required to advance this research agenda.

\section{Empirical work}

Using a selection of the few studies that have focused on the family structure-family functioning-health nexus, we reflect on how this research mirrors these two exemplars of a causal model. In a recent study, Donley et al. [40] apply regression analysis to cross-sectional data collected from the parents of American children with special needs. The authors conclude that socio-economic factors are less impactful on delayed care than family dynamics. Yet, the SES and family functioning variables are included in two separate regression models rather than jointly entered into the same model, with no moderator analysis for SES and without taking family structure into account. In another of these studies, Sawyer et al. [41] applied regression analysis to cross-sectional data collected from a sample of parents of Australian children with asthma to determine the association of family structure (single versus twoparent families) and family functioning with health-related quality of life. Both family structure and functioning, treated as independent covariates, were found to be associated with mental health, while only family structure was associated with physical health and social functioning. 


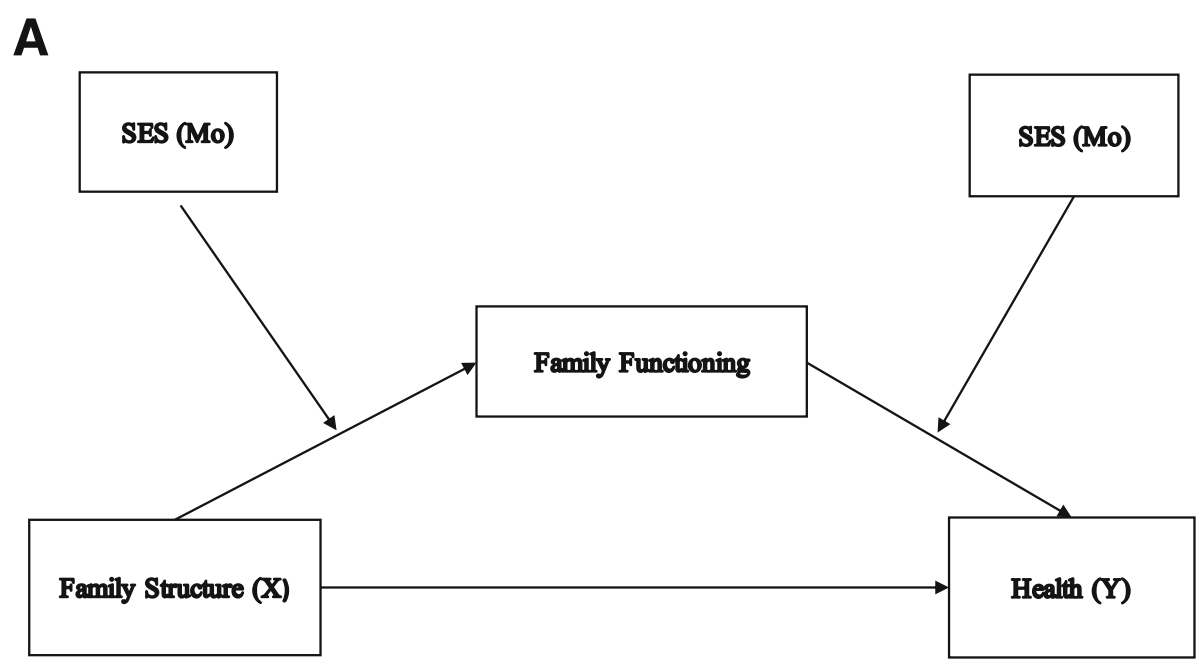

B

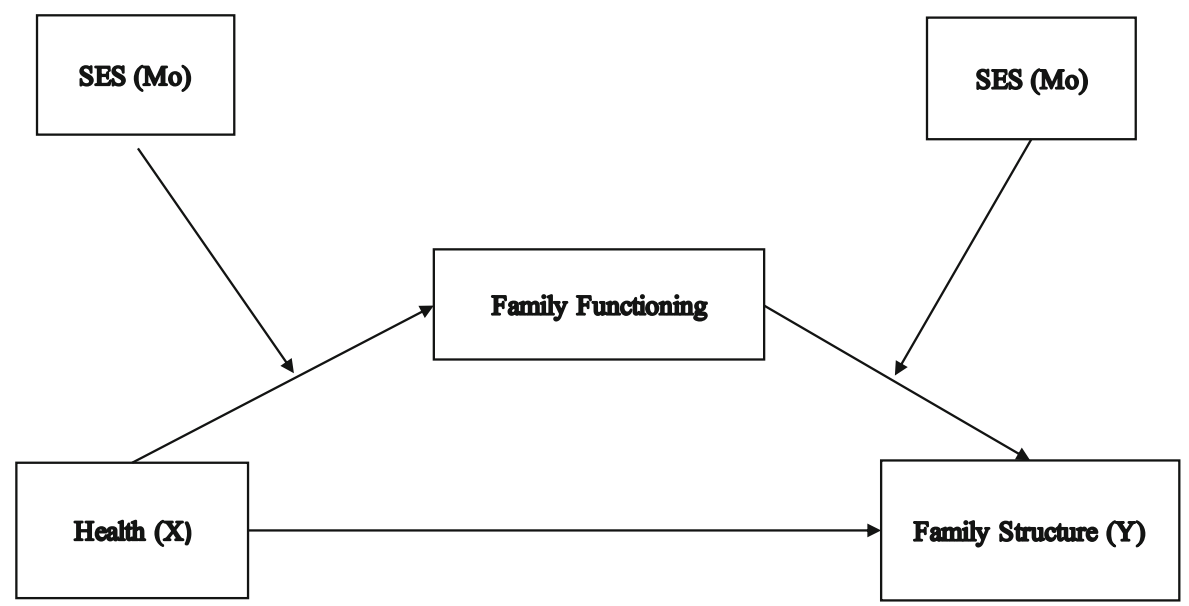

Fig. 1 a: A moderated mediation model with health as an outcome. Note: Adapted from Fig. 6 [39]. b: A moderated mediation model with health as a determinant. Note: Adapted from Fig. 6 [39]

Cheng et al. [42], in another recent study, examined the effects of family structure and functioning on mental health using regression analysis of cross-sectional household survey data from China. The authors found that only family functioning was associated with mental health and not family structure. Pless et al. [43], in a much earlier cross-sectional study on psychological adjustment in American school children with chronic physical disorders, also treated family structure and family functioning as independent covariates and SES as a control. Although individually significant, these authors did not explore the potential interaction between family structure and functioning. Wagner et al. [32], however, employ a longitudinal design in which the study outcome (substance use among American adolescents) was observed a year after family structure, functioning and other covariates, including SES. Using a Structural Equation Model (SEM), the authors do explore the nature of the mediating relationship in Fig. 1a and Fig. 2b and found that parental monitoring mediated the association of parental family structure with substance use. Again, however, as was the case in each of the other studies, SES was simply treated as a controlled covariate rather than a potentially important moderator of the family's role as a SDH.

Among the handful of studies that we could locate that explore the impact of child and adult health on family functioning $[8,44-47]$ and family structure [48], which found that health negatively impacted family functioning [44-47] and modified family structure [48], SES generally is entirely omitted from the multivariate analysis $[8,44,47,48]$. The only exception is Treyvaud et al. [46], who incorporated a measure of SES (employment status) into a multi-dimensional index of 'social risk', which was then employed as a controlled covariate. 


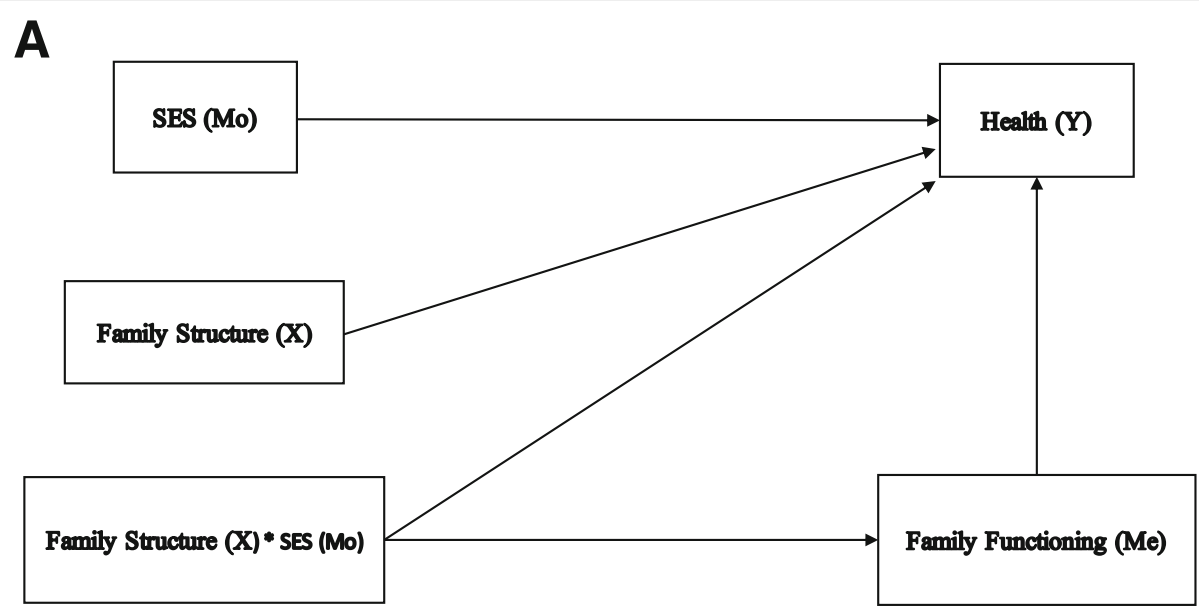

B

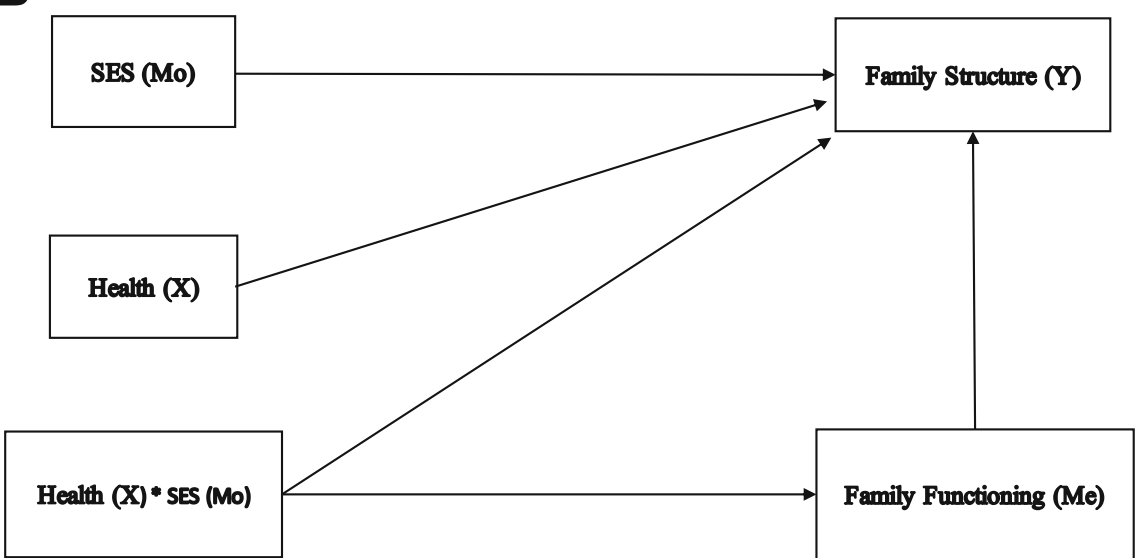

Fig. 2 a: A mediated moderation model with health as an outcome. Note: Adapted from Fig. 7 [39]. b: A mediated moderation model with health as a determinant. Note: Adapted from Fig. 7 [39]

\section{Future directions}

To inform the development and evaluation of interventions, it is necessary to elucidate the wider causal mechanisms through which specific dimensions of family functioning are impacted by and acts on health and health-related behaviours, and how these dynamic processes play out over the life course and across generations in families with different structures. A first step in this endeavour is to build more nuanced and integrated causal models of the complex mechanics of the interplay between the constructs of socioeconomic status, family functioning, family structure and health, using the conceptual causal models presented here as a starting point. The second step is to develop and implement longitudinal research designs that will yield the necessary empirical data to test these theories, either comprehensively or more realistically in a piecemeal fashion, in both clinical but also general populations, scaling this research to more representative levels to allow a public health perspective. A key component of this part of the research agenda includes the development of multi-dimensional short-form scales of family functioning with good psychometric properties for use in general populations. Also, researchers need to consider collecting information on the perceptions of family functioning from all family members in the defined family structure [49]. Such assessments are often disparate [49] and measures of such discrepancy may themselves warrant consideration as a measure of family functioning. In each case, such theoretical and empirical research endeavours should be appropriately contextualised, including cross-culturally. The final step would be to apply state-of-the-art techniques for longitudinal analysis to these data. Given that all four these central variables coevolve over time, latent growth modelling is of particular importance [50], as are autoregressive latent trajectories models [51]. There is also scope for expanded analyses of the valuable data collected in the various studies already conducted in this field to help further elucidate the complexities of these relationships. Such endeavour is inter- and multi-disciplinary at its core, requiring social scientists such as economists and sociologists to join health scientists and statisticians in demystifying the family's role as a key SDH and health consequence. 


\section{Abbreviations}

SDH: Social determinants of health; SEM: Structural equation model SES: Socioeconomic status; WHO: World health Organization

\section{Acknowledgements}

None.

\section{Authors' contributions}

FB1, FB2 and EW co-conceptualised and co-wrote the manuscript. FB1, FB2 and $\mathrm{EW}$ all read and approved the final manuscript.

\section{Funding}

None.

\section{Availability of data and materials}

Not applicable.

\section{Ethics approval and consent to participate}

Not applicable.

\section{Consent for publication}

Not applicable.

\section{Competing interests}

The authors declare that they have no competing interests.

\section{Author details}

1 School of Economics and Finance, University of the Witwatersrand Jan Smuts Avenue, Braamfontein 2050 Johannesburg South Africa ${ }^{2}$ Melbourne Institute: Applied Economic \& Social Research, The University of Melbourne, Melbourne, Australia. ${ }^{3}$ ARC Centre of Excellence for Families and Children Over the Life Course, Melbourne, Australia. ${ }^{4}$ Faculty of Social Sciences, University of Antwerp, Antwerp, Belgium.

Received: 15 November 2019 Accepted: 11 January 2021

Published online: 22 January 2021

\section{References}

1. Braveman P, Egerter S, Williams DR. The social determinants of health: coming of age. Annu Rev Public Health. 2011:32(1):381-98.

2. WHO Commission on Social Determinants of Health, World Health Organization, editor. Closing the gap in a generation: health equity through action on the social determinants of health: Commission on Social Determinants of Health final report: Geneva, Switzerland, World Health Organization, Commission on Social Determinants of Health; 2008. p. 246.

3. Blas E, Sommerfeld J, Kurup AS, World Health Organization, Special Programme for research and training in tropical diseases, Alliance for Health Policy and Systems Research, et al. Social determinants approaches to public health: from concept to practice. Geneva: World Health Organization; 2011. p. 209.

4. Marmot M, Allen J, Bell R, Bloomer E, Goldblatt P. WHO European review of social determinants of health and the health divide. Lancet. 2012;380(9846): 1011-29.

5. Solar O, Irwin A. A conceptual framework for action on the social determinants of health. [Internet]. Geneva: World Health Organization; 2010. Available from: https://www.who.int/sdhconference/resources/ ConceptualframeworkforactiononSDH_eng.pdf.

6. Barrett AE, Turner RJ. Family structure and mental health: the mediating effects of socioeconomic status, family process, and social stress. J Health Soc Behav. 2005;46(2):156-69.

7. Keitner GI, Heru AM, Glick ID. Clinical manual of couples and family therapy. Washington DC: American Psychiatric Publishing Inc; 2010.

8. Brown JS, Rawlinson ME, Hardin DM. Family functioning and health status. J Fam Issues. 1982;3(1):91-110

9. Hosoda T. The impact of childhood Cancer on family functioning: a review. Grad Stud J Psychol. 2014;15:18-30.

10. Bambara JK, Wadley V, Owsley C, Martin RC, Porter C, Dreer LE. Family functioning and low vision: a systematic review. J Vis Impair Blind. 2009; 103(3):137-49.
11. Holtom-Viesel A, Allan S. A systematic review of the literature on family functioning across all eating disorder diagnoses in comparison to control families. Clin Psychol Rev. 2014;34(1):29-43.

12. Halliday JA, Palma CL, Mellor D, Green J, Renzaho AMN. The relationship between family functioning and child and adolescent overweight and obesity: a systematic review. Int J Obes. 2014;38(4):480-93.

13. Lewandowski AS, Palermo TM, Stinson J, Handley S, Chambers CT. Systematic review of family functioning in families of children and adolescents with chronic pain. J Pain. 2010;11(11):1027-38.

14. Cousino MK, Rea KE, Schumacher KR, Magee JC, Fredericks EM. A systematic review of parent and family functioning in pediatric solid organ transplant populations. Pediatr Transplant. 2017;21(3):e12900.

15. Van Schoors M, Caes L, Knoble NB, Goubert L, Verhofstadt LL, Alderfer MA Systematic review: associations between family functioning and child adjustment after pediatric cancer diagnosis: a meta-analysis. J Pediatr Psychol. 2017:42(1):6-18

16. Leeman J, Crandell JL, Lee A, Bai J, Sandelowski M, Knafl K. Family functioning and the well-being of children with chronic conditions: a metaanalysis: FAMILY FUNCTIONING. Res Nurs Health. 2016:39(4):229-43.

17. Psihogios AM, Fellmeth $H$, Schwartz LA, Barakat LP. Family functioning and medical adherence across children and adolescents with chronic health conditions: a meta-analysis. J Pediatr Psychol. 2019;44(1):84-97.

18. Ryan SM, Jorm AF, Toumbourou JW, Lubman DI. Parent and family factors associated with service use by young people with mental health problems: a systematic review: family factors associated with service use. Early Interv Psychiatry. 2015;9(6):433-46.

19. Deatrick JA. Where is "family" in the social determinants of health? Implications for family nursing practice, research, education, and policy. J Fam Nurs. 2017;23(4):423-33.

20. McNeill T. Family as a social determinant of health. Healthc Q. 2010;14:60-7.

21. Russell LT, Coleman M, Ganong L. Conceptualizing family structure in a social determinants of health framework: conceptualizing family structure. J Fam Theory Rev. 2018;10(4):735-48.

22. Agate ST, Zabriskie RB, Eggett DL. Praying, playing, and successful families: an examination of family religiosity, family leisure, and family functioning. Marriage Fam Rev. 2007:42(2):51-75.

23. Bernstein GA, Borchardt CM. School refusal: family constellation and family functioning. J Anxiety Disord. 1996:10(1):1-19.

24. Brown SL, Manning WD. Family boundary ambiguity and the measurement of family structure: the significance of cohabitation. Demography. 2009; 46(1):85-101.

25. Clark AF, Barrett L, Kolvin I. Inner city disadvantage and family functioning. Eur Child Adolesc Psychiatry. 2000;9(2):77-83.

26. Freistadt J, Strohschein L. Family structure differences in family functioning: interactive effects of social capital and family structure. J Fam Issues. 2013; 34(7):952-74.

27. Hayden LC, Schiller M, Dickstein S, Seifer R, Sameroff S, Miller I, et al. Levels of family assessment: I. Family, marital, and parent-child interaction. J Fam Psychol. 1998;12(1):7-22

28. Herzer M, Godiwala N, Hommel KA, Driscoll K, Mitchell M, Crosby LE, et al. Family functioning in the context of pediatric chronic conditions. J Dev Behav Pediatr. 2010;31(1):26-34.

29. Hornberger LB, Zabriskie RB, Freeman P. Contributions of family leisure to family functioning among single-parent families. Leis Sci. 2010;32(2):143-61.

30. McFarlane AH, Bellissimo A, Norman GR. Family structure, family functioning and adolescent well-being: the transcendent influence of parental style. J Child Psychol Psychiatry. 1995:36(5):847-64

31. Shek DTL, Xie Q, Lin L. The impact of family intactness on family functioning, parental control, and parent-child relational qualities in a chinese context. Front Pediatr. 2015;2. [cited 2019 Oct 28] Available from: http://journal.frontiersin.org/article/https://doi.org/10.3389/fped.2014.00149/ abstract

32. Wagner KD, Ritt-Olson A, Chou C-P, Pokhrel P, Duan L, Baezconde-Garbanati $L$, et al. Associations between family structure, family functioning, and substance use among Hispanic/Latino adolescents. Psychol Addict Behav. 2010:24(1):98-108

33. Yeung JWK, Chan Y-C. Family functioning of Chinese families in an impoverished neighborhood in Hong Kong. Psychol Rep. 2010;107(3):740-8.

34. Banovcinova A, Levicka J, Veres $M$. The impact of poverty on the family system functioning. Procedia Soc Behav Sci. 2014:132:148-53. 
35. Li X, Zou H, Liu Y, Zhou Q. The relationships of family socioeconomic status, parent-adolescent conflict, and filial piety to adolescents' family functioning in mainland China. J Child Fam Stud. 2014;23(1):29-38.

36. Mansfield AK, Dealy JA, Keitner GI. Family functioning and income: does low-income status impact family functioning? Fam J. 2013;21(3):297-305.

37. Botha F, Booysen F, Wouters E. Family functioning and socioeconomic status in south African families: a test of the social causation hypothesis. Soc Indic Res. 2018;137(2):789-811.

38. Botha F, Wouters E, Booysen F. Happiness, socioeconomic status, and family functioning in south African households: a structural equation Modelling approach. Appl Res Qual Life. 2018;13(4):947-89.

39. Wu AD, Zumbo BD. Understanding and using mediators and moderators. Soc Indic Res. 2008;87(3):367-92.

40. Donley T, King DM, Nyathi N, Okafor A, Mbizo J. Socioeconomic status, family functioning and delayed care among children with special needs. Soc Work Public Health. 2018;33(6):366-81.

41. Sawyer MG, Spurrier N, Whaites L, Kennedy D, Martin AJ, Baghurst P. The relationship between asthma severity, family functioning and the healthrelated quality of life of children with asthma. Qual Life Res. 2000;9(10): 1105-15.

42. Cheng $Y$, Zhang $L$, Wang $F$, Zhang $P$, Ye B, Liang $Y$. The effects of family structure and function on mental health during China's transition: a crosssectional analysis. BMC Fam Pract. 2017;18(1):59.

43. Pless IB, Roghmann K, Haggerty RJ. Chronic illness, family functioning, and psychological adjustment: a model for the allocation of preventive mental health services. Int J Epidemiol. 1972;1(3):271-7.

44. Heru AM, Ryan CE, Vlastos K. Quality of life and family functioning in caregivers or relatives with mood disorders. Psychiatr Rehabil J. 2004;28(1): 67-71.

45. McFarlane AC. Family functioning and overprotection following a natural disaster: the longitudinal effects of post-traumatic morbidity. Aust N Z J Psychiatry. 1987;21(2):210-8.

46. Treyvaud K, Doyle LW, Lee KJ, Roberts G, Cheong JIY, Inder TE, Anderson PJ. Family functioning, burden and parenting stress 2 years after very preterm birth. Early Hum Dev. 2011;87:427-31.

47. Ulus Y, Tander B, Akyol Y, Ulus A, Tander B, Bilgici A, Kuru O, Akbas S. Functional disability of children with spina bifida: its impact on parents' psychological status and family functioning. Dev Neurorehabil. 2012;15(5): 322-8.

48. Corman H, Kaestner R. The effects of child health on marital status and family structure. Demography. 1992;29(3):389-408.

49. Georgiades K, Boyle MH, Jenkins JM, Sanford M, Lipman E. A multilevel analysis of whole family functioning using the McMaster family assessment device. J Fam Psychol. 2008;22(3):344-54.

50. Muniz-Terrera G, Robitaille A, Kelly A, Johansson B, Hofer S, Piccinin A. Latent growth models matched to research questions to answer questions about dynamics of change in multiple processes. J Clin Epidemiol. 2017 Feb;82:158-66

51. Pakpahan E, Hoffmann R, Kröger H. Statistical methods for causal analysis in life course research: an illustration of a cross-lagged structural equation model, a latent growth model, and an autoregressive latent trajectories model. Int J Soc Res Methodol. 2017;20(1):1-19.

\section{Publisher's Note}

Springer Nature remains neutral with regard to jurisdictional claims in published maps and institutional affiliations.

Ready to submit your research? Choose BMC and benefit from:

- fast, convenient online submission

- thorough peer review by experienced researchers in your field

- rapid publication on acceptance

- support for research data, including large and complex data types

- gold Open Access which fosters wider collaboration and increased citations

- maximum visibility for your research: over $100 \mathrm{M}$ website views per year

At BMC, research is always in progress.

Learn more biomedcentral.com/submissions 